\title{
Thoracic aortic endografting facilitates the resection of tumors infiltrating the aorta
}

\author{
Stephane Collaud, MD, MSc, ${ }^{\mathrm{a}}$ Thomas K. Waddell, MD, PhD, ${ }^{a}$ Kazuhiro Yasufuku, MD, PhD, ${ }^{\mathrm{a}}$ \\ George Oreopoulos, MD, MSc, ${ }^{\mathrm{b}}$ Raj Rampersaud, MD, ${ }^{\mathrm{c}}$ Barry Rubin, MD, PhD, ${ }^{\mathrm{b}}$ \\ Graham Roche-Nagle, MD, ${ }^{\mathrm{b}}$ Shaf Keshavjee, MD, MSc, ${ }^{\mathrm{a}}$ and Marc de Perrot, MD, MSc ${ }^{\mathrm{a}}$
}

\begin{abstract}
Objectives: We and others have reported the early experience with off-label use of thoracic aortic endografts to facilitate the resection of tumors infiltrating the aorta. We describe our extended experience and long-term outcome using this innovative approach.
\end{abstract}

\begin{abstract}
Methods: Patients with preoperative suspected thoracic aortic infiltration who underwent endografting followed by en bloc tumor resection including the aortic wall were retrospectively reviewed and data were analyzed.

Results: Between 2008 and 2012, 5 patients (4 female) with a median age of 52 years (34-63 years) were included. Tumors infiltrating the aorta were non-small cell lung carcinomas $(\mathrm{n}=3)$ and $\operatorname{sarcomas}(\mathrm{n}=2)$. Both patients with sarcoma had neoadjuvant radiation, whereas patients with non-small cell lung carcinomas had neoadjuvant $(\mathrm{n}=2)$ or adjuvant chemoradiation $(\mathrm{n}=1)$. Aortic endografting was performed 1 to 17 days before resection of the tumor. The proximal end of the stent-graft was deployed in the aortic arch $(n=2)$ or the descending aorta $(n=3)$. The tumor was resected en bloc in all patients and combined with chest wall and 2 to 3 levels of spinal resection in 4 of the 5 patients. Two patients with full-thickness aortic wall resection had additional buttressing of the defect. Cardiopulmonary bypass was never required. One patient had an empyema requiring debridements and thoracic window. After a median follow-up of 39 months (range, 9-62 months), all patients were alive and disease-free. None of them had overt endograft-related complications.
\end{abstract}

Conclusions: Thoracic aortic endografting allowed safe en bloc resection of tumors invading the aortic wall. Therefore, the indication for thoracic aortic endografts could be extended to specific oncologic cases. (J Thorac Cardiovasc Surg 2014;147:1178-82)

Surgical resection of tumors invading the aorta is a challenging procedure. It usually implies cardiopulmonary bypass with or without hypothermia and circulatory arrest. ${ }^{1}$ The use of a passive shunt to avoid extracorporeal circulation also has been described. ${ }^{2}$ More recently, we and others reported the use of thoracic aortic endografts to facilitate en bloc resection of tumors invading the aortic wall. ${ }^{3-5} \mathrm{We}$ describe our updated surgical experience and long-term outcome using this innovative approach.

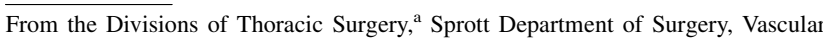
Surgery, ${ }^{\mathrm{b}}$ Sprott Department of Surgery, and the Peter Munk Cardiac Centre, and Orthopedic Surgery, ${ }^{c}$ Sprott Department of Surgery, Toronto General Hospital, University Health Network and the University of Toronto, Toronto, Ontario, Canada.

Dr Collaud was supported for this work by the American Association for Thoracic Surgery's Evarts A. Graham Memorial Traveling Fellowship.

Disclosures: Authors have nothing to disclose with regard to commercial support.

Read at the 93rd Annual Meeting of The American Association for Thoracic Surgery, Minneapolis, Minnesota, May 4-8, 2013.

Received for publication May 6, 2013; revisions received July 18, 2013; accepted for publication Dec 9, 2013; available ahead of print Jan 31, 2014.

Address for reprints: Marc de Perrot, MD, MSc, Division of Thoracic Surgery, University of Toronto, Toronto General Hospital 9N-961, 200 Elizabeth St, Toronto, Ontario M5G 2C4, Canada (E-mail: marc.deperrot@uhn.ca).

$0022-5223 / \$ 36.00$

Copyright (c) 2014 by The American Association for Thoracic Surgery

http://dx.doi.org/10.1016/j.jtcvs.2013.12.020

\section{MATERIALS AND METHODS}

This is a retrospective single-center study. Patients with preoperative suspected tumoral infiltration of the thoracic aorta who underwent endografting followed by en bloc resection of the tumor and aortic wall were included. Data were retrospectively retrieved from patients' electronic charts. The study was approved by the institutional research ethics board at University Health Network. Patient informed consent was obtained.

\section{Preoperative Staging}

In case of non-small cell lung cancer, preoperative evaluation comprised computed tomography (CT) of the chest and abdomen, CT or magnetic resonance imaging (MRI) of the brain, bone scan, or integrated positron emission tomography with CT. MRI of the spine was performed when its infiltration was suspected. The mediastinum was systematically assessed by cervical mediastinoscopy or endobronchial ultrasoundguided fine-needle aspiration. Induction therapy consisted of concurrent chemoradiation with 2 cycles of cisplatin-etoposide and 45 Gy to the primary tumor. Restaging was performed with CT of the chest/abdomen, brain MRI or CT, and spine MRI if necessary. Tumors were classified according to the 7 th edition of the TNM classification of malignant tumors. 6

In case of sarcoma, preoperative radiotherapy with $50 \mathrm{~Gy}$ in 25 fractions was administered to the tumor. Pre- and post-radiotherapy imaging was performed with CT or MRI of the chest.

\section{Surgical Technique}

Surgical procedures were performed in 2 or 3 stages. Insertion of the thoracic aortic endograft was performed before en bloc tumor resection. Endografting was indicated if the preoperative CT showed evidence of aortic compression or encircling on more than $180^{\circ}$. Tumor resection 


\section{Abbreviations and Acronyms \\ $\mathrm{CT}=$ computed tomography \\ MRI = magnetic resonance imaging}

was performed en bloc in a second stage, typically a few days after the aortic endograft insertion. If the tumor involvement implied 3 vertebral levels or more, a 2-stage procedure was performed for the spine resection as previously described.

Before thoracic aortic endografting, CT angiography from the supraaortic vessels to the common femoral arteries was performed to assess for vessel size and anatomy. In instances of planned coverage of aortic arch arteries, sealing of artery take-off followed by appropriate arterial bypass or endovascular in situ fenestration via ipsilateral brachial artery was performed during the same stage. In cases of inadequately sized external iliac vessels, retroperitoneal access was used. An activated clotting time of 300 seconds or more was targeted for the whole procedure. Endografts (Talent and Valiant from Medtronic Inc, Minneapolis, Minn) were upsized by $10 \%$ or less compared with the native aorta. A proximal and distal landing zone of $4 \mathrm{~cm}$ of healthy aorta was targeted for sufficient endograft stability. Postprocedure CT angiogram was performed to rule out endoleak.

Tumor resection was performed en bloc and included resection of the involved aortic wall, lung, chest wall, and spine when necessary. Typical 2-stage procedure consisted of a posterior midline incision, posterior tumor release, and multilevel spine instrumentation for the first stage. In the second stage, en bloc tumor resection with completion of the spine instrumentation was performed through a posterolateral thoracotomy with or without reopening of the posterior midline incision. The chest wall was reconstructed with a polypropylene (Marlex; C. R. Bard Inc, Cranston, NJ) or polytetrafluoroethylene (Gore-Tex; WL Gore \& Associates, Flagstaff, Ariz) mesh.

\section{RESULTS}

Between 2008 and 2012, 5 patients underwent insertion of a thoracic aortic endograft to facilitate en bloc resection of a tumor infiltrating the aortic wall. Patient characteristics are described in Table 1. After a median follow-up of 39 months (range, 9-62 months), all patients were alive and disease-free.

All 5 patients underwent aortic wall resection without aortic clamping and cardiopulmonary bypass. Table 2 summarizes the different types of combined surgical procedures performed. R0 resection was achieved in all patients. The median hospital length of stay for the sum of the 2- or 3 -stage procedure was 16 days (range, 7-29 days). None of the 5 patients had endograft-related complications, such as paraplegia, stroke, endoleak, and graft migration. Only 1 patient had major postoperative complications.

The early outcome of patients 1 and 2 have been described in detail by Roche-Nagle and associates. ${ }^{3}$ Patient 1 had a history of multiple local recurrences of a low-grade chest chondosarcoma. She presented with a new recurrence at the level of the 8th thoracic vertebra (T8) and indenting the posterior aspect of the aorta. The first surgical procedure consisted of a posterior midline incision with posterior spinal instrumentation T3-T12 and bilateral laminectomy for resection of spinous processes T7-9. Four days later, she underwent a straightforward insertion of a thoracic endovascular graft above the artery of Adamkiewicz. The third stage occurred 2 days later through a thoracotomy and reopening of the posterior midline incision (Figure 1). Complete resection of the tumor required resection of the whole aortic wall over $5 \times 3 \mathrm{~mm}$ exposing the endograft. The aortic defect was covered with pleura. Six weeks after discharge, she underwent a thoracic window for empyema secondary to parenchymal bronchopleural fistula, and an omental flap was brought to cover the area of the involved spine and aorta. After multiple wound and instrumentation revisions for debridement and nonunion, the patient remains disease-free at more than 5 years and is receiving intermittent antibiotic therapy for minor hemoptysis. Clear evidence of graft infection has not been established.

Patient 2 had a lung adenocarcinoma of the left upper lobe involving the dome of the aortic arch. After a crossover bypass from the right to the left common carotid artery was performed (end-to-side anastomosis, 7-mm Dacron graft), an endograft was deployed proximally up to the take-off of the innominate artery with rapid ventricular pacing. The endovascular graft covered the left common carotid and subclavian arteries. To minimize the risk of endoleak, the origin of the left carotid was ligated and an endovascular plug was placed in the left proximal subclavian artery. Five days later, the patient underwent en bloc tumor resection via a left hemi-clamshell incision, including the media of the aorta on one quarter of the aortic circumference and a width of $3 \mathrm{~cm}$ (Table 2). Adjuvant chemoradiotherapy with $4 \mathrm{cy}$ cles of cisplatin-vinorelbine and 60 Gy was administered. The patient is alive without recurrence 53 months after the surgery.

Patient 3 had multiple metachronous lung metastasis from a femur osteosarcoma. After repeated resections, recurrence was apparent as a pleural mass located behind the aorta at the level of the carina on the left side (Figure 2). A straightforward endograft insertion allowed a partial aortic wall resection of $3 \mathrm{~cm}^{2}$, en bloc with the tumor on the following day. Tumor recurred in a different location along the pleura 13 months later requiring another chest wall resection, and the patient is currently disease-free at 39 months.

Patient 4 underwent a 3-stage procedure for a left lower lobe adenocarcinoma invading the neural foramen of T6-7. The endovascular graft was deployed $2 \mathrm{~cm}$ below the left subclavian artery. Six days later, she underwent posterior tumor release and instrumentation/stabilization from T2-10. Finally, the tumor could be resected en bloc with an area of $5 \mathrm{~cm}^{2}$ of aortic adventitium 11 days later.

Patient 5 had a squamous cell carcinoma of the left lower lobe abutting the descending aorta over $180^{\circ}$ and infiltrated T6 vertebral body. The stent-graft was deployed at the distal edge of the origin of the left common carotid artery, covering the subclavian artery origin. Therefore, in situ fenestration of the subclavian artery with balloon dilation 
TABLE 1. Patient characteristics

\begin{tabular}{|c|c|c|c|c|c|c|c|}
\hline Patient no. & Sex & Preoperative therapy & Histology & (y)pTNM & Postoperative therapy & DFS (mo) & Recurrence \\
\hline 1 & Female & Radiation & Sarcoma & - & - & 62 & - \\
\hline 2 & Male & - & NSCLC & T4NOM0 & Chemoradiation & 53 & - \\
\hline 3 & Female & Radiation & Sarcoma & - & - & 13 & Local \\
\hline 4 & Female & Chemoradiation & NSCLC & T4NOM0 & - & 30 & - \\
\hline 5 & Female & Chemoradiation & NSCLC & T3N0M0 & - & 9 & - \\
\hline
\end{tabular}

$D F S$, Disease-free survival; NSCLC, non-small cell lung cancer.

was performed through an arteriotomy of the left axillary artery. An iliac conduit (10-mm Dacron, end-to-side anastomosis) was used to safely accommodate the aortic stentgraft delivery system because the diameter of the femoral artery was too small. En bloc tumor resection was performed 2 weeks later. A full-thickness aortic wall resection was required to completely remove the tumor exposing the aortic endograft over $3 \mathrm{~cm}$ in width and $5 \mathrm{~cm}$ in length. Because the aortic stent started to protrude through the aortic wall defect leading to some bleeding from the distal insertion of the stent, the aortic defect was buttressed with bovine pericardium to refrain the stent expansion throughout the large aortic defect and stop the bleeding (Figure 3). An additional left latissimus dorsi muscle flap, which had been preserved at the time of the thoracotomy, was brought on the aorta and the bronchovascular stumps. After a 9-month follow-up, the patient has not had any complication related to the endograft and remains free of disease.

\section{DISCUSSION}

The first successful cases of endovascular stent-graft insertions were described in 1991 and 1994 for abdominal and thoracic aortic aneurysms, respectively. ${ }^{8,9}$ Currently, endovascular thoracic stent-grafts are commonly used for aortic aneurysms, dissection, traumatic injury, and rupture. We described the off-label use of these endografts in the oncologic setting for 5 patients and provided long-term outcome data. Advantages of aortic endografting over open surgery are linked to its minor invasiveness and absence of requirement of cardiopulmonary or aortoaortic bypass use at the time of surgery. ${ }^{10-12}$ The absence of bypass-related anticoagulation during the tumor resection phase allowed safe major en bloc resection as in our series. This was particularly helpful in case of spine involvement by the tumor, where spine resection invariably leads to profuse blood loss.

Some technical characteristics and pitfalls need to be emphasized. The optimal delay between thoracic aortic endograft insertion and aortic wall resection is not known. In an experimental study involving endovascular stentgrafting of the descending aorta of mongrel dogs, histologic examination of the aortic wall revealed inflammation and remodeling leading to progressive graft embedment. ${ }^{13}$ Indeed, full-thickness aortic wall resection was described as "easy" immediately after stent-grafting and "difficult" 7 days later because of aortic wall inflammation and dense adhesions between the aorta and the stent-graft. In our series, the median delay was 5 days (range, 1-17 days). We had never performed aortic endografting and resection during the same anesthesia. This lapse of time allowed us to assess the patient both clinically and radiologically for potential complications of stent-grafting, such as paraplegia or endoleaks, before proceeding with resection of the tumor.

TABLE 2. Surgical procedures

\begin{tabular}{|c|c|c|c|c|c|c|c|c|c|}
\hline \multirow[b]{3}{*}{ Patient no. } & \multirow{3}{*}{$\begin{array}{l}\text { No. of } \\
\text { stages }\end{array}$} & \multicolumn{2}{|c|}{ Aortic endografting } & \multicolumn{6}{|c|}{ En bloc resection } \\
\hline & & \multirow{2}{*}{$\begin{array}{c}\text { Proximal } \\
\text { landing zone }\end{array}$} & \multirow{2}{*}{$\begin{array}{l}\text { Additional } \\
\text { procedure }\end{array}$} & \multirow[b]{2}{*}{ Lung } & \multirow{2}{*}{$\begin{array}{l}\text { Chest } \\
\text { wall }\end{array}$} & \multicolumn{2}{|c|}{ Spine } & \multicolumn{2}{|c|}{ Aorta } \\
\hline & & & & & & Vertebrectomy & Instrumentation & Resection & Reinforcement \\
\hline 1 & 3 & $\begin{array}{l}\text { Descending } \\
\text { aorta }\end{array}$ & - & $\begin{array}{l}\text { Wedge } \\
\text { lower lobe }\end{array}$ & Ribs 7-9 & Hemi T7-9 & Posterior & $\begin{array}{l}\text { Adventitia- } \\
\text { media-intima }\end{array}$ & Parietal pleura \\
\hline 2 & 2 & Aortic arch & $\begin{array}{l}\text { Carotid-carotid } \\
\text { crossover }\end{array}$ & $\begin{array}{l}\text { Upper } \\
\text { lobectomy }\end{array}$ & - & - & - & Adventitia-media & - \\
\hline 3 & 2 & $\begin{array}{l}\text { Descending } \\
\text { aorta }\end{array}$ & - & $\begin{array}{l}\text { Lower } \\
\text { lobectomy }\end{array}$ & Ribs 5-7 & Partial T5-6 & - & Adventitia-media & - \\
\hline 4 & 3 & $\begin{array}{l}\text { Descending } \\
\text { aorta }\end{array}$ & - & $\begin{array}{l}\text { Lower } \\
\text { lobectomy }\end{array}$ & Ribs 5-7 & Hemi T5-7 & Posterior & Adventitia & - \\
\hline 5 & 2 & Aortic arch & $\begin{array}{c}\text { In situ fenestration } \\
\text { of subclavian a }\end{array}$ & $\begin{array}{l}\text { Lower } \\
\text { lobectomy }\end{array}$ & Rib 5-8 & Partial T5-8 & - & $\begin{array}{l}\text { Adventitia- } \\
\text { media-intima }\end{array}$ & $\begin{array}{l}\text { Bovine } \\
\text { pericardium, } \\
\text { latissimus } \\
\text { dorsi muscle }\end{array}$ \\
\hline
\end{tabular}




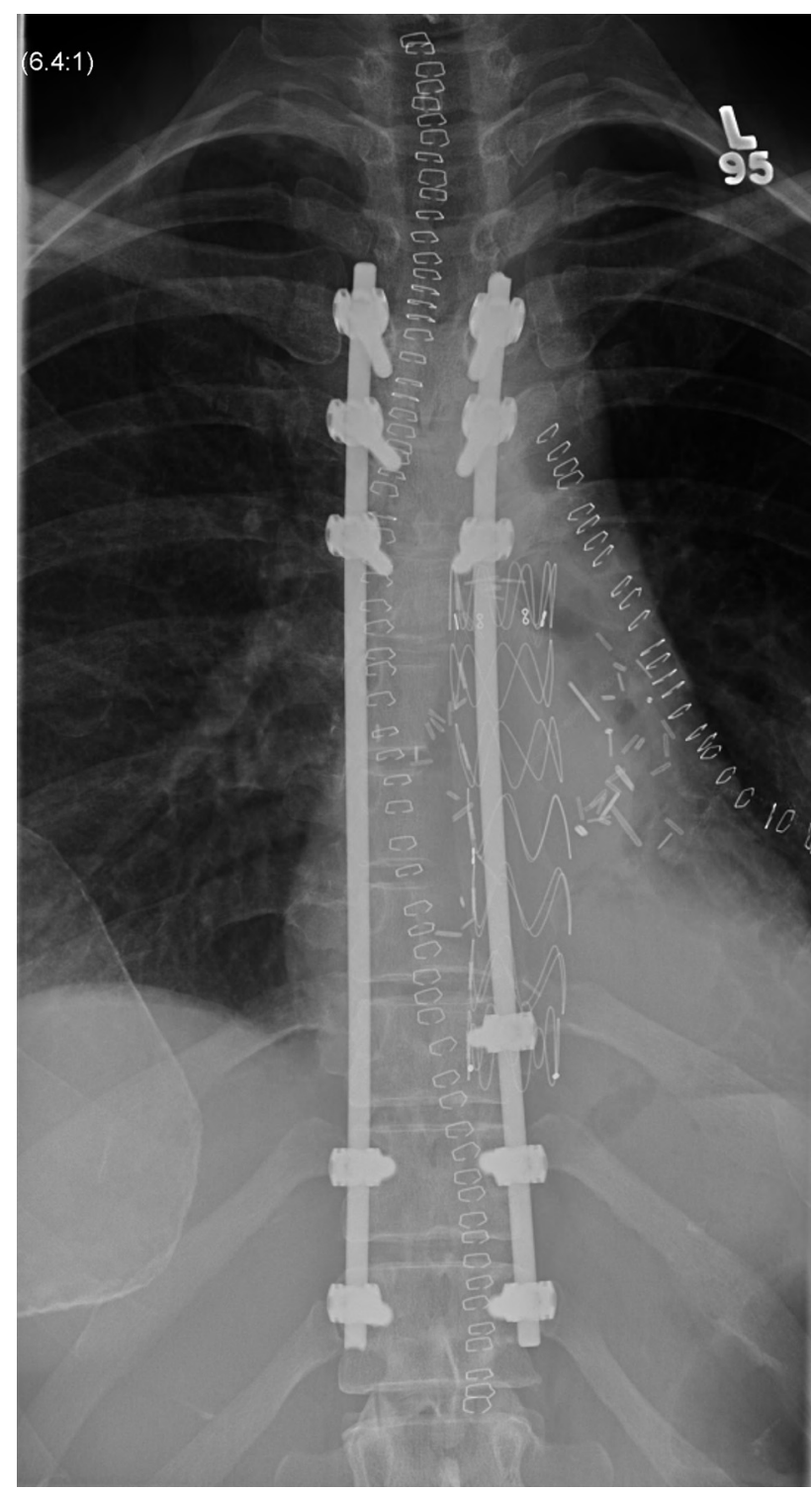

FIGURE 1. Anteroposterior spine x-ray after posterior spinal instrumentation of T3-12 vertebras (first stage), endovascular stent-grafting of the descending thoracic aorta (second stage), and en bloc tumor resection (third stage). Note the hemivertebrectomy T7-9 and resection of their corresponding ribs.

Data on the maximal possible extent of aortic wall resection are lacking. In the previously cited experimental study, full- or partial-thickness of the aortic wall (adventitia and outer half of the media) was resected on $1 \mathrm{~cm}$ in width and on one half or one quarter of the circumference. ${ }^{13}$ There was no complication reported at 1 year except for resection of one half of the aortic circumference. In fact, stenosis of the aorta with proximal dilatation was detected at 6 months and stable in size at 12 months on angiography. Because this extensive aortic wall resection was not covered with a free fascia patch compared with others, the authors could not

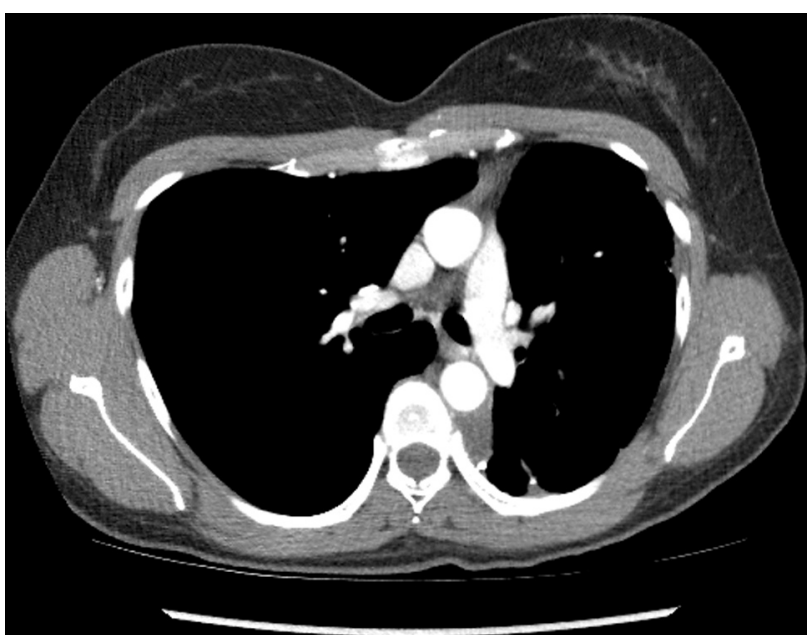

FIGURE 2. Preoperative axial CT view showing a lung metastasis from an osteosarcoma invading the aortic wall.

conclude whether the extent of the resection or the absence of covering was responsible for the aortic narrowing.

In our current series and 2 other reported cases, no complication was encountered when partial-thickness of the aortic wall and less than one half of the circumference were resected. ${ }^{4,5}$ We encountered bulging of the endograft out of the aortic wall defect in 1 patient after fullthickness wall resection over $5 \mathrm{~cm}$. However, this complication could be well managed with buttressing of the defect with a patch of bovine pericardium. Large landing zones for the endograft on healthy aorta are probably an important component in stent-graft stability. We and others aimed to stent the suspected area of aortic infiltration with a safe proximal and distal margin of $4 \mathrm{~cm}$ of uninvolved aorta. At the end of follow-up, none of our 2 patients had endoleak or pseudoaneurysm formation.

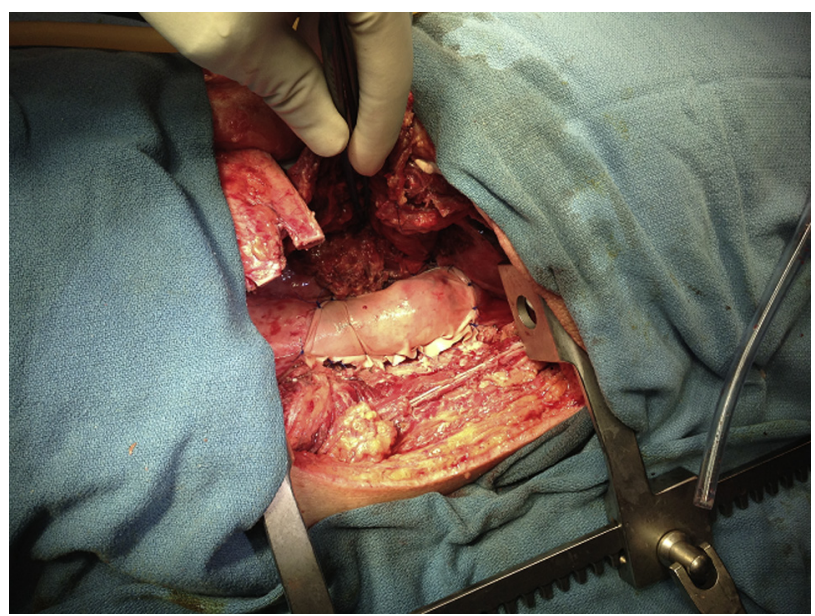

FIGURE 3. Intraoperative view showing buttressing of the aortic fullthickness defect with bovine pericardium, anchored with interrupted 4.0 Prolene. 
Aortic wall defect buttressing has been described with patches of abdominal rectus muscle fascia, parietal pleura, bovine pericardium, omentum, or latissimus dorsi muscle. ${ }^{4,5,13}$ In the study by Sasahara and colleagues, ${ }^{13}$ histologic examination of the abdominal rectus muscle fascia patch used to cover aortic defect showed a thicker collagenous tissue than in any other aortic wall region. Therefore, aortic defect buttressing may strengthen the aortic wall, increasing stent-graft stability and potentially avoiding dangerous aortic fistula with neighboring structures.

\section{CONCLUSIONS}

In our experience, thoracic aortic endografting allowed safe en bloc resection of tumors invading the aortic wall. This option was particularly helpful for tumors extending into the aortic wall and the spine. Therefore, we suggest the extension of indication for thoracic aortic endograft to specific oncologic cases. Routine preoperative aortic imaging, including transesphageal echocardiography and intravascular ultrasound, may help better define the indication for endografting and should be assessed in the future.

\section{References}

1. Tsuchiya R, Asamura H, Kondo H, Goya T, Naruke T. Extended resection of the left atrium, great vessels, or both for lung cancer. Ann Thorac Surg. 1994;57: 960-5.

2. Nakahara K, Ohno K, Mastumura A, Hirose H, Mastuda H, Nakano S, et al. Extended operation for lung cancer invading the aortic arch and superior vena cava. J Thorac Cardiovasc Surg. 1989;97:428-33.

3. Roche-Nagle G, de Perrot M, Waddell TK, Oreopoulos G, Rubin BB. Neoadjuvant aortic endografting. Ann Vasc Surg. 2009;23:787.e1-5.

4. Marulli G, Lepidi S, Frigatti P, Antonello M, Grego F, Rea F. Thoracic aorta endograft as an adjunct to resection of a locally invasive tumor: a new indication to endograft. J Vasc Surg. 2008;47:868-70.

5. Berna P, Bagan P, De Dominicis F, Dayen C, Douadi Y, Riquet M. Aortic endostent followed by extended pneumonectomy for T4 lung cancer. Ann Thorac Surg. 2011;91:591-3.

6. Vallieres E, Shepherd FA, Crowley J, Van Houtte P, Postmus PE, Carney D, et al. The IASLC Lung Cancer Staging Project: proposals regarding the relevance of TNM in the pathologic staging of small cell lung cancer in the forthcoming (seventh) edition of the TNM classification for lung cancer. J Thorac Oncol. 2009;4: 1049-59.

7. Anraku M, Waddell TK, de Perrot M, Lewis SJ, Pierre AF, Darling GE, et al. Induction chemoradiotherapy facilitates radical resection of T4 non-small cell lung cancer invading the spine. J Thorac Cardiovasc Surg. 2009;137:441-7.e1.

8. Parodi JC, Palmaz JC, Barone HD. Transfemoral intraluminal graft implantation for abdominal aortic aneurysms. Ann Vasc Surg. 1991;5:491-9.

9. Dake MD, Miller DC, Semba CP, Mitchell RS, Walker PJ, Liddell RP. Transluminal placement of endovascular stent-grafts for the treatment of descending thoracic aortic aneurysms. N Engl J Med. 1994;331:1729-34.
10. Ohta M, Hirabayasi H, Shiono H, Minami M, Maeda H, Takano H, et al. Surgical resection for lung cancer with infiltration of the thoracic aorta. J Thorac Cardiovasc Surg. 2005;129:804-8.

11. Klepetko W, Wisser W, Birsan T, Mares P, Taghavi S, Kupilik N, et al. T4 lung tumors with infiltration of the thoracic aorta: is an operation reasonable? Ann Thorac Surg. 1999;67:340-4.

12. de Perrot M, Fadel E, Mussot S, de Palma A, Chapelier A, Dartevelle P. Resection of locally advanced (T4) non-small cell lung cancer with cardiopulmonary bypass. Ann Thorac Surg. 2005;79:1691-7.

13. Sasahara H, Sueyoshi S, Tanaka T, Fujita H, Shirouzu K. Evaluation of an aortic stent graft for use in surgery on esophageal cancer involving the thoracic aorta: experimental study. Jpn J Thorac Cardiovasc Surg. 2004; 52:231-9.

\section{Discussion}

Dr Mathew Williams (New York, NY). In terms of staging, did you do these all at the same time or did you place the endograft previously and then bring them back? In the patients in whom you reconstructed the aorta, how did you control the aorta? Did you clamp it or use an endo-occlusion balloon?

Dr Collaud. All these patients were staged before the aortic endografting. All of our patients with non-small cell lung cancer had T4 N0 lung cancer. We never clamp the aorta in any of our patients.

Dr Williams. How soon before the resection did you do the endograft?

Dr Collaud. The endografting has been done from the first day up to the 17 th day. The longest delay was 17 days.

Dr Williams. But always at least 1 day?

Dr Collaud. Yes. We have never done both the endografting and the resection during the same anesthesia to assess the patient both clinically and radiologically for potential endograft-related complications.

Dr Osman Al-Radi (Jeddah, Saudi Arabia). Is there a limit to how much invasion of the aorta there has to be for this to be feasible, like if the invasion is more than half of the circumference of the aorta? Have you decided when not to do this in terms of circumference and length?

Dr Collaud. The widest excision we performed was in patient 5 , who had infiltration of half of the circumference of the aorta and about the width of $4 \mathrm{~cm}$. From this, I think half of the circumference is the biggest aortic wall defect we can do if we remove the full thickness.

There is an experimental study performed in mongrel dogs in which they removed half of the circumference, and they also started to have complications at the site of resection of the wall. So it is probably safer to resect less than half of the circumference. 